\title{
Parasitic infections represent a significant health threat among recent immigrants in Chicago
}

\author{
Jesica A. Herrick ${ }^{1}$ (D) Monica Nordstrom ${ }^{2}$ - Patrick Maloney ${ }^{2} \cdot$ Miguel Rodriguez $^{2} \cdot$ Kevin Naceanceno $^{3} \cdot$ Gloria Gallo $^{3,4}$. \\ Rojelio Mejia ${ }^{3} \cdot$ Ron Hershow ${ }^{1,2}$
}

Received: 3 September 2019 / Accepted: 14 January 2020 / Published online: 1 February 2020

(C) The Author(s) 2020

\begin{abstract}
Parasitic infections are likely under-recognized among immigrant populations in the USA. We conducted a cross-sectional study to evaluate if such infections have health impacts among recent immigrants in Chicago and to identify predictive factors for parasitic infections. A total of 133 recent immigrants were enrolled, filling out a standardized medical questionnaire and providing blood and stool samples. Appriximately $12 \%$ of subjects $(15 / 125)$ who provided a blood or stool sample for testing were found to have evidence of current or prior infection with a pathogenic parasite, of which Toxocara spp. (8 subjects, 6.4\%) and Strongyloides stercoralis (5 subjects, $4 \%$ ) were most commonly identified. Parasitic infection was more likely among subjects who had immigrated within the previous 2 years and those with a self-reported history of worms in the stool. The most useful surrogate markers identified for parasitic infections were an elevated immunoglobulin E level (seen in 46.7\% (7/15) of subjects with parasitic infections and 20\% (22/110) of uninfected individuals, $p=0.04)$ and the presence of Blastocystis hominis cysts on Ova \& Parasite exam (detected in 38.5\% (5/13) of subjects with parasitic infections who provided a stool sample and $5.1 \%$ (5/98) of uninfected subjects, $p=0.002$ ). Our study found that parasitic infections may be common in recent US immigrants, which highlights an important health disparity among a vulnerable population that merits further study. Additionally, clinical risk factors, symptoms, and laboratory findings traditionally thought to be associated with parasites were commonly found but not predictive of infection in this study population.
\end{abstract}

Keywords Immigrant health $\cdot$ Strongyloidiasis $\cdot$ Blastocystis $\cdot$ Toxocara $\cdot$ Giardia

Handling Editor: Julia Walochnik

Electronic supplementary material The online version of this article (https://doi.org/10.1007/s00436-020-06608-4) contains supplementary material, which is available to authorized users.

Jesica A. Herrick

Christe5@uic.edu

Monica Nordstrom

monicapcn@gmail.com

Patrick Maloney

pmalon@1suhsc.edu

Miguel Rodriguez

migrodri23@gmail.com

Kevin Naceanceno

naceance@ outlook.com

Gloria Gallo

ggalloe.biotec@gmail.com

Rojelio Mejia

rojelio.mejia@bcm.edu
Ron Hershow

rchersho@uic.edu

1 Department of Medicine, Division of Infectious Diseases, Immunology, and International Medicine, University of Illinois at Chicago, 808 South Wood, M/C 735, Chicago, IL 60612, USA

2 University of Illinois at Chicago School of Public Health, Chicago, IL, USA

3 Department of Medicine, Section of Infectious Diseases, National School of Tropical Medicine, Baylor College of Medicine, Houston, TX, USA

4 Science and Technology Institute, Federal University of São Paulo, São José dos Campos, São Paulo, Brazil 


\section{Introduction}

Among select populations within the USA, parasitic diseases are thought to be an under-recognized public health problem (Garg et al. 2005; Hotez 2007; Hotez 2008; Hotez 2014; Hotez et al. 2012; Jariwala et al. 2017; Parise et al. 2014). Although exact numbers are not available, studies have suggested that within the USA there may be up to 300,000 people with Chagas disease (Bern et al. 2011; Bern and Montgomery 2009; Leiby et al. 2002; Manne-Goehler et al. 2016; Sarkar et al. 2010; Schmunis and Yadon 2010; Zaniello et al. 2012), 1.3-2.8 million with serological evidence of exposure to Toxocara spp. (Hotez 2008; Liu et al. 2018), 4 million with soil-transmitted helminths (Hotez 2008; Posey et al. 2007; Safdar et al. 2004), 1.2 million with giardiasis (Adams et al. 2017), 41,400-169,000 with cysticercosis (Hotez 2008), and approximately 8000 with schistosomiasis (Hotez 2008).

US immigrant populations are believed to be at increased risk for parasitic infections, as many immigrants come from areas where some parasites are endemic (Arena et al. 2011; Hotez 2008; Meymandi et al. 2017; Ostera and Blum 2016; Ostera et al. 2017). Whereas refugees to the USA undergo thorough screening coupled with treatment of infectious diseases prior to arrival, legal immigrants (who may have similar risk factors as refugees) are only required to undergo screening for infectious diseases of significant public health importance, such as tuberculosis. As would be expected, illegal immigrants are not screened for any infections. Upon arrival to the USA, immigrants may be more likely to have a decreased socioeconomic status and therefore frequently reside in the underserved areas within the USA (characterized by increased poverty rates, impaired access to healthcare, and a high percentage of households with suboptimal plumbing) that are thought to have an increased prevalence of parasitic infections (Hotez 2007; Hotez 2008; Hotez 2014; McKenna et al. 2017). This population thus possesses a dual risk for parasites, either acquired from their country of origin or following emigration to the USA (Parise et al. 2014). However, published prevalence estimates vary widely, and there is little data regarding the current impact of these infections in the USA.

Both diagnostic and methodologic problems have impeded research regarding parasitic infections among US immigrants. Diagnostic inaccuracies can occur because laboratory tests for parasites can have significant limitations including poor sensitivities and lack of availability in the community (BelhassenGarcia et al. 2014; Hotez 2014; Jariwala et al. 2017; Ostera and Blum 2016; Parise et al. 2014; Posey et al. 2007; Shulman et al. 1997). Further, the primary method of diagnosis for many parasitic infections, serologic testing, has several important shortcomings, including an inability to distinguish between active and past infections, cross-reactivity between different parasites, and in many cases a reduced sensitivity due to the focal nature of some parasitic diseases (Khurana and Sethi 2017; Maddison 1991; Ndao 2009). Methodologic limitations to research studies may also partly account for these widely varying prevalence estimates (Garg et al. 2005; Hotez 2008; Hotez 2014). For example, past estimates of Chagas disease prevalence were based on testing of blood donors, which has been shown to underestimate the number of infected individuals (Bern et al. 2008). A second commonly used method creates an estimate based on the number of immigrants living in the USA and disease prevalence in endemic regions. However, infection risks among those who emigrated may be different from that of the general population within a given country (Arena et al. 2011; Bern and Montgomery 2009; Conners et al. 2016; Crum et al. 2003; Perez-Molina et al. 2012; Schmunis and Yadon 2010).

Many of the published studies evaluating health impacts of parasitic infections on immigrants either screened for only a small number of parasites or screened immigrants from a single country (Bern et al. 2011; Bern and Montgomery 2009; Ostera and Blum 2016; Ostera et al. 2017; Rapoport et al. 2015; Sarkar et al. 2010; Won et al. 2008; Zaniello et al. 2012). Improved data regarding these health impacts is badly needed as parasitic infections can have significant morbidity (Fitzpatrick et al. 2010; Hotez 2007; Hotez 2008; Hotez et al. 2012; Jariwala et al. 2017; Parise et al. 2014; Posey et al. 2007; Starr and Montgomery 2011). For example, Chagas disease causes cardiomyopathy and/or esophageal or colonic dilation in up to 20 $30 \%$ of those infected (Bern et al. 2011; Moncayo and Ortiz Yanine 2006); those with toxocariasis may have an increased risk for asthma (Buijs et al. 1997; Cobzaru et al. 2012; Kanobana et al. 2013; Walsh 2011); and intestinal parasite infection has been associated with delayed cognitive development and impaired nutrition in some studies (Ezeamama et al. 2005; Yap et al. 2012). Parasitic infections have also been shown to increase the severity of illnesses due to other infectious diseases such as tuberculosis and HIV (Garg et al. 2005).

This study was conducted with the overall aim of assessing if parasitic infections are a significant health problem among recent immigrants, as currently there are few studies that have addressed this question. As many of the symptoms of parasitic infections are nonspecific, an additional objective of our study was to identify if there are symptoms, signs, or laboratory tests that could be used in this population as predictors of the presence of parasites.

\section{Materials and methods}

Compliance with ethical standards The study was approved by the Institutional Review Board of the University of Illinois at Chicago, and written informed consent was obtained from all participants. For Spanish-speaking individuals, consent was obtained using consent and/or assent forms translated into 
Spanish. Subjects who spoke languages other than English or Spanish had the consent form explained to them in their language of preference (using an interpreter). For enrolled individuals between the ages of 10 and 18, the subject signed an assent form, and a parent or guardian signed a parental permission form. Each participant received $\$ 40$ to compensate them for their time. Treatment for parasitic infections was not a part of the study, but all subjects were offered the possibility of seeing one of the study authors $(\mathrm{JH})$ in clinic free of charge to discuss treatment options.

Study design Patients were enrolled for this cross-sectional study between November 2014 and July 2016. Subjects were recruited through collaboration with local community organizations that provide services to immigrants and through a mass email sent to students enrolled at the University of Illinois at Chicago. Subjects were also recruited from community health clinics as long as they were accessing the healthcare system for reasons clearly unrelated to a parasitic infection (e.g., patients presenting for routine physical exams). Subjects were eligible for inclusion if they were ages 10-80 and an immigrant living in the US mainland for less than 5 years and were originally from Africa, Asia, South America, Central America, Mexico, the Caribbean islands, or Puerto Rico. Although they are US citizens and not immigrants from non-US territories, Puerto Ricans were specifically included in this study because previous research suggested that parasitic infections were common among the Puerto Rican population in Chicago (Winsberg et al. 1975). The 5year time point for living in the USA was chosen based on the average expected life-span of hookworms, Ascaris lumbricoides, and Trichuris trichiura, a primary focus of our investigations (Jourdan et al. 2017). Subjects were excluded from the study if they (1) were currently pregnant, as the immunosuppression of pregnancy may alter the presentation and one of the aims of the study was to identify factors predictive of parasitosis, or (2) had taken antiparasitic medications since moving to the continental USA.

Upon enrollment, a standardized questionnaire (Online Resource - Supplemental Appendix) was administered to collect information regarding demographics, risk factors for parasitic infections, and symptoms. Participants then provided clinical samples to be tested for evidence of parasitic infections as described below.

Laboratory testing Whole blood for a complete blood count was collected in an ethylenediaminetetraacetic acid (EDTA) tube and processed in the clinical laboratory at the University of Illinois at Chicago (BXH 800 or BXH 1600, Beckman Coulter, Brea, CA) within $12 \mathrm{~h}$. Serum samples were collected in a serum separator tube (SST) and centrifuged within $1 \mathrm{~h}$ of collection. A portion of the supernatant was sent for measurement of immunoglobulin E (IgE) level (Quantitative
ImmunoCAP® Fluorescent Enzyme Immunoassay, Arup Laboratories, Salt Lake City, UT). The remainder of the supernatant was stored at $-80^{\circ} \mathrm{C}$ until samples were shipped as a batch to the Centers for Disease Control and Prevention, where serologic testing was performed for infections endemic to each subject's country of origin (Online Resource Table 1).

Antibody responses to cysticercosis, strongyloidiasis, and toxocariasis were determined using a multiplex bead-based assay, MBA (Anderson et al. 2015; Hernandez-Gonzalez et al. 2017; Rascoe et al. 2015). For cysticercosis, three recombinant antigens (rGP50, rT24H, and sTs18var1) were used; one recombinant antigen was used for both strongyloidiasis (Ss-NIE-1) and toxocariasis (rTc-CTL-1). The assays were conducted and interpreted according to previously published methods (Anderson et al. 2015; Hernandez-Gonzalez et al. 2017; Rascoe et al. 2015).

Antibody against $T$. cruzi antigens was detected using a commercial kit (Weiner Lab, Argentina) and by following the company protocol instructions (Affranchino et al. 1989; Chagatest: ELISA recombinante v. 3.0. Rosario n.d.; da Silveira et al. 2001). All serum specimens were initially tested by FAST-ELISA using Schistosoma mansoni adult microsomal antigen and then by a species-specific immunoblot appropriate to the subject's country of origin according to previously published methods (Hancock and Tsang 1986; Tsang and Wilkins 1991; Tsang and Wilkins 1997).

Patients also provided a stool sample for standard Ova \& Parasite (O\&P) direct microscopy (Arup Labs Qualitative Concentration/Trichrome Stain/Microscopy, Salt Lake City, UT) and a multi-parallel quantitative polymerase chain reaction (qPCR) which tests for eight common gastrointestinal pathogens (Ancylostoma, Ascaris, Cryptosporidium, Entamoeba, Giardia, Necator, Strongyloides, and Trichuris). Only one stool sample was requested for O\&P due to our desire to compare O\&P directly with qPCR and because the yield of collecting multiple samples for O\&P exam for any new identifiable pathogens has been shown to be low in immigrant populations (Bass et al. 1992). The stool samples for qPCR were frozen without fixatives at $-80^{\circ} \mathrm{C}$ and shipped as a batch to the Baylor College of Medicine where the DNA was extracted using the MP FastDNA for Soil Kit (MP Biomedicals, Solon, $\mathrm{OH}$ ) and qPCR were conducted according to previously published methods (Cimino et al. 2015; Mejia et al. 2013; Weatherhead et al. 2017).

Statistical analysis Statistical analyses were performed using Prism 7 (GraphPad, San Francisco, CA) and SAS (Cary, NC). Data were summarized by using frequency with percentage for categorical variables. For continuous variables, geometric mean with standard deviation or median with range or interquartile range was used. For categorical variables, prevalence ratios (PR) were used to evaluate relationships between covariates and the main outcome (the presence of a parasitic 
infection), and Fisher's exact test or chi-squared test were used to determine significance. Mann-Whitney $U$ test was used to evaluate for associations between continuous variables and the presence of a parasite. Correlations were calculated using Spearman's rank correlation coefficient. Kappa values were used to compare results from stool O\&P exam to qPCR testing.

\section{Results}

Patient characteristics Seven hundred and thirty-eight people were approached about the study, and 133 were enrolled (Online Resource Fig. 1). All enrolled subjects filled out the study questionnaire (unedited results shown in Online Resource Table 2); 94\% of enrolled subjects (125/133) provided blood, and 85\% (113/133) provided stool samples for testing. The mean age of enrolled subjects was 32 years, and $45.1 \%$ (60/133) were male (Table 1). Participants came from 28 different countries. As shown in Table 1, many subjects reported having been exposed to risk factors for parasitic infection.

Laboratory testing The median IgE among the 125 subjects from whom blood samples were obtained was $57 \mathrm{IU} / \mathrm{mL}$ (range 3-7732), and $23.2 \%$ of subjects (29/125) had elevated IgE levels. Twelve subjects $(9.8 \%)$ were found to have eosinophilia, and the median absolute eosinophil count (AEC) level was 200 cells/UL (range $0-1600$ cells/UL, Table 1 ).

Parasitic infections Twelve percent (15/125) of subjects who provided a clinical sample for testing were found to have evidence of current or prior infection with a pathogenic parasite species. As shown in Table 2, the most common infections identified were Toxocara spp., seen in eight subjects $(6.4 \%)$, followed by $S$. stercoralis (five subjects, $4 \%$, Table 2 ).

Outcome assessment There were no significant differences in symptoms, exposures, or laboratory results between those found to be mono-infected with each of the different parasite species detected. Consequently, for our primary analysis, we compared uninfected individuals to subjects with evidence for any pathogenic parasitic infection with infected subjects treated as a single group.

A large number of subjects (10/111 subjects who provided a sample for O\&P testing, 9\%) were found to have B. hominis. Although the pathogenicity of $B$. hominis remains controversial (Andersen and Stensvold 2016; Roberts et al. 2014), infection with this organism in our sample was not associated with any significant differences in symptoms or laboratory values compared to the uninfected group. Accordingly, in our analysis $B$. hominis was not included as a pathogenic parasitic infection.
Demographic characteristics and exposure histories of subjects with parasitic infections Nearly all of the subjects found to have evidence of a pathogenic parasite $(14 / 15$, $93.3 \%$ ) had lived in the continental USA for 2 years or less (compared to 70/110 of those who were uninfected, $63.6 \%$, PR $6.8, p=0.02$, Table 3 ). This history was therefore a very sensitive, though not specific, marker for parasitic infections (sensitivity $93.3 \%$, specificity $36.4 \%$, PPV 16.7\%, NPV 97.6\%). No other demographic variables, including age, gender, recruitment site, or region of origin differed significantly between those with and without infections (Online Resource Table 3).

A self-reported history of ever having seen worms in the stool was also associated with evidence of current or prior parasitic infection $(8 / 15,53.3 \%$ in the infected group reported this history versus $18 / 110,16.4 \%$, in the uninfected group, $p=0.003$, PR 4.4, Table 3). This history appeared to be a nonspecific marker and was equally common among those diagnosed with enteric parasites compared to those with non-enteric parasites ( $p$ value $=0.8$ ). Other classic risk factors for parasitic infections (close contact with animals, etc.), although commonly reported among study participants, did not differ between groups (all $p$ values $\geq 0.05$, Online Resource Table 3).

In the year prior to study enrollment, subjects with evidence of parasitic infections had experienced an overall increased number of physical complaints (median 8 ) compared to those with no evidence of parasites $(4, p=0.02)$. However, symptoms typically thought of as indicative of parasitic infections (rash, pruritus, etc.) did not differ significantly between the groups (all $p$ values $>0.05$ for symptoms experienced both the day of study enrollment and within the previous year, Online Resource Table 3).

Laboratory values in subjects with evidence of parasitic infections Both the median IgE level (249 IU/mL) and the proportion of subjects with an increased IgE level ( 7 of 15 subjects, $46.7 \%$ ) were significantly increased in subjects with evidence for parasitic infections compared to those who were uninfected (median IgE 52 IU/mL, 22/110, 20\%, subjects with elevated IgE level, both $p$ values $<0.05$, Table 3 and Online Resource Table 4). Increases in IgE were not associated with a history of seasonal allergies and/or asthma (all $p$ values $=$ NS). The difference in median IgE levels between groups remained statistically significant when subjects $<18$ years old were excluded from analysis (as normal values for $\operatorname{IgE}$ are higher in this group). Although an elevated IgE level was a relatively specific finding for parasitic infections (specificity $80 \%$, NPV 92\%), this finding was not a sensitive marker of infection (sensitivity 47\%, PPV 24\%).

The median AEC did not differ between those with and without evidence of a parasitic infection (Online Resource Table 4). Despite a low sensitivity for parasites (20\%, PPV 
Table 1 Demographics, symptoms, and laboratory results of 133 enrolled subjects

Characteristic

Results $^{\mathrm{a}}$

Age, mean years (standard deviation)

$32(17.3)$

Gender, male/female, $\mathrm{N}$ (\% male)

$60: 73(45.1)$

Country/region of origin, $\mathrm{N}(\%)$

Asia (excluding India)

$33(24.8)$

Mexico

$30(22.6)$

India

$26(19.5)$

Central/South America

$22(16.5)$

Africa

Middle East

USA (Puerto Rico) ${ }^{\mathrm{b}}$

$13(9.8)$

$5(3.8)$

$4(3)$

Mean number of years in school (standard deviation)

$9.9(5.2)$

Annual household income in US dollars, N (\%)

$<20,000$

95 (71.4)

$20,000-40,000$

$30(22.6)$

$40,000-60,000$

$5(3.8)$

$60,000-100,000$

$2(1.5)$

$>100,000$

Length of time living in the continental $\mathrm{USA}^{\mathrm{c}}$, mean years

$1(0.8)$

(range, standard deviation in years)

Raised in rural environment, N (\%)

2 (10 days -5 years, 1.6$)$

Exposure history prior to immigration, number yes $(\%)$

Frequently walked barefoot

$25(18.8)$

Close contact with animals

$65(48.9)$

Used a well as source of drinking water

$65(48.9)$

Bathed in streams or ponds

$58(43.6)$

$25(18.8)$

Lived in a house with a thatched roof

$46(34.6)$

Symptoms rith arted by the prion to emigration, number yes (\%)

$32(24.1)$

Gastrointestinal

$25(18.8)$

Constitutional

$25(18.8)$

Musculoskeletal

$13(9.8)$
$12(9)$

Dermatologic

Pulmonary

$10(7.5)$

Cardiovascular

$3(2.3)$

Immunoglobulin E (IgE) results

Subjects with elevated Immunoglobulin E, N (\%)

Immunoglobulin $\mathrm{E}$ level, IU/mL, median (range, standard deviation)

$29 / 125^{\mathrm{e}}(23.2)$

$57(3-7732,706)$

Absolute eosinophil count (AEC) results

Subjects with elevated absolute eosinophil count, N (\%)

$12 / 123^{\mathrm{f}}(9.8)$

Absolute eosinophil count, median cells $/ \mu$ (range, standard deviation)

$200(0-1600,240)$

Pathogenic parasitic infection, N (\%)

$15 / 125^{\mathrm{g}}(12)$

${ }^{\text {a }}$ Unedited results from all enrolled subjects are shown in Online Resource Table 2; $N$ number of subjects

${ }^{\mathrm{b}}$ Although they are US citizens and not immigrants from non-US territories, Puerto Ricans were specifically included in this study because previous research suggested that parasitic infections were common among the Puerto Rican population in Chicago

${ }^{\mathrm{c}}$ Potential range (due to enrollment criteria) $0-5$ years

${ }^{\mathrm{d}}$ Gastrointestinal symptoms included heartburn, difficulty or pain with swallowing, abdominal pain, diarrhea, and nausea/vomiting; constitutional symptoms included weight loss, fatigue, fevers, and weakness; musculoskeletal symptoms included pain and stiffness in the joints or myalgias; dermatologic included itching, hives, or rash; pulmonary symptoms included wheezing, shortness of breath, and cough; cardiovascular included chest pain, palpitations, or irregular heart beat; and allergic symptoms included those who responded "yes" to the question "do you currently have any symptoms of seasonal allergies"

${ }^{\mathrm{e}}$ Of the 125 subjects who underwent a blood draw, normal value of IgE defined as $<696 \mathrm{IU} / \mathrm{mL}$ for subjects 10-12 years old, $<629$ for those ages $13-15$, $<537$ for those ages $16-17$, and $<214 \mathrm{IU} / \mathrm{mL}$ in adults

${ }^{\mathrm{f}}$ For two of the 125 subjects who underwent a blood draw, a complete blood count was unable to be performed due to clotting of the blood sample, normal AEC defined as $<500$ cells/UL

${ }^{\mathrm{g}}$ Of 125 subjects who provided a clinical sample (blood or stool) for testing

$25 \%$ ), however, eosinophilia was relatively specific to subjects with evidence of parasitic infection (specificity $91.8 \%$, NPV $89.4 \%)$.
The presence of cysts of $B$. hominis on O\&P exam was strongly associated with an increased likelihood for infection with a pathogenic parasite species. About 39\% (5/13) of 
Table 2 Parasitic infections diagnosed among recent immigrants living in Chicago

Parasitic infections

Number of subjects infected (\%)

Soil-transmitted helminths

Toxocara spp.

$8(6.4)^{\mathrm{a}}$

Strongyloides stercoralis

$5(4)^{\mathrm{b}}$

Trichuris trichiura

$2(1.8)^{\mathrm{c}}$

Ascaris lumbricoides

$1(0.9)^{\mathrm{c}}$

Protozoa

Giardia duodenalis

$4(3.5)^{\mathrm{d}}$

Nonpathogenic or disputed pathogenicity species ${ }^{\mathrm{e}}$

Blastocystis hominis

Endolimax nana

Dientamoeba fragilis

Iodamoeba bütschlii, Entamoeba coli, Entamoeba hartmanni

1 each $(0.9)$

Number of subjects with multiple pathogens

$3(2.4)^{\mathrm{f}}$

Comparison of Ova \& Parasite Exam to qPCR for pathogenic species ${ }^{\mathrm{g}}$

Ova \& Parasite positive

qPCR positive

1

Ova \& Parasite negative

qPCR negative

0

107

${ }^{\text {a }}$ Of 125 subjects who provided blood samples for testing, all 8 subjects were diagnosed based on a positive serologic test

${ }^{\mathrm{b}}$ Of 125 subjects who provided blood and/or stool samples for testing, 1 subject tested negative on O\&P but positive on both serology and stool qPCR, 3 subjects had a positive serologic test but negative O\&P and qPCR, and 1 subject had a positive serology but did not provide a stool sample for testing

${ }^{\mathrm{c}}$ Diagnosed based on a positive stool qPCR test, of 113 subjects who provided a stool sample for qPCR testing

${ }^{\mathrm{d}}$ Of 113 subjects who provided a stool sample for testing, 1 subject tested positive on both qPCR and O\&P tests, and 3 subjects tested positive on qPCR but negative on $O \& P$

${ }^{\mathrm{e}}$ Of 111 subjects who returned a stool sample for O\&P testing, all infections diagnosed based on a positive on O\&P exam as these nonpathogenic or disputed pathogenicity organisms were not tested for on qPCR

${ }^{\mathrm{f}}$ Of 125 subjects who provided blood and/or stool samples for testing, one subject had positive stool qPCR tests for both Ascaris and Trichuris and a positive serologic test for Toxocara, 1 subject had positive stool qPCR tests for Trichuris and Giardia as well as positive serologic testing for Toxocara, and the third subject had positive serologic testing and stool qPCR for $S$. stercoralis and positive serologic testing for Toxocara

${ }^{\mathrm{g}} p$ value $=0.07$, sensitivity of O\&P compared to qPCR $12.5 \%$, specificity $100 \%$, positive predictive value (PPV) $100 \%$, negative predictive value (NPV) $93.9 \%$, kappa 0.21

subjects in the parasite positive group who returned a stool sample had a positive O\&P for Blastocystis, compared to 5\% $(5 / 98)$ tested for O\&P exam in the uninfected group $(p=$ $0.002, \mathrm{PR}=6.3$, Table 3).

\section{Discussion}

Despite the fact that many US immigrants come from areas where parasitic infections are endemic, it is not known if these infections are currently an important health issue among immigrant populations. In response to this deficit, we conducted a comprehensive evaluation for the presence of a broad array of parasitic infections in recent immigrants in Chicago. We found that $12 \%$ of recent immigrants in our sample had evidence of prior or current infection with a pathogenic parasite species.

Although limited by the small number of subjects found to have evidence of parasitic infection, our study still identified a few key factors which were significantly more likely in subjects with evidence of parasites: a self-reported history of having previously observed worms in the stool, having immigrated within the past 2 years, and reporting a relatively high number of nonspecific physical ailments within the previous year. Our results also highlight that clinical risk factors (contact with animals and frequently walking barefoot), symptoms (including urticaria, rash, and diarrhea), and laboratory findings (eosinophilia) traditionally thought to be associated with parasites were commonly found but not predictive of infection in this study population. If confirmed in a larger sample, these results suggest that practitioners should have a high degree of suspicion for parasitic infections when evaluating recent immigrants regardless of the presence or absence of symptoms or laboratory abnormalities.

Our study results showed that a high percentage of recent immigrants had evidence of current or prior infection with a few key pathogenic parasites, including S. stercoralis, Toxocara spp., and G. lamblia. Positive serologic testing for $S$. stercoralis has been shown to be associated with a high likelihood of active ongoing 
Table 3 Findings associated with the presence of a parasitic infection

\begin{tabular}{|c|c|c|c|c|}
\hline Demographics & $\begin{array}{l}\text { Uninfected } \\
N=110\end{array}$ & $\begin{array}{l}\text { Parasitic infection }^{\text {a }} \\
N=15\end{array}$ & $\begin{array}{l}\text { Prevalence ratio } \\
\text { (95\% confidence interval) }\end{array}$ & $P$ value \\
\hline \multicolumn{5}{|l|}{ Length of time living in the USA, $\mathrm{N}(\%)$} \\
\hline $\begin{array}{l}>2 \text { years } \\
\leq 2 \text { years } \\
\text { Mean age (standard deviation) }\end{array}$ & $\begin{array}{l}40(36.4) \\
70(63.6) \\
31(16.4)\end{array}$ & $\begin{array}{l}1(6.7) \\
14(93.3) \\
37.5(21.6)\end{array}$ & $\begin{array}{l}\text { Reference } \\
6.8(0.9-50.2) \\
1.0(1.0-1.1)\end{array}$ & $\begin{array}{l}0.02 \\
0.2\end{array}$ \\
\hline \multicolumn{5}{|l|}{ Gender, N (\%) } \\
\hline $\begin{array}{l}\text { Female } \\
\text { Male } \\
\text { Childhood exposures (in country of origin), } \\
\quad \text { number of respondents reporting exposure (\%) }\end{array}$ & $\begin{array}{l}58(52.7) \\
52(47.3)\end{array}$ & $\begin{array}{l}8(53.3) \\
7(46.7)\end{array}$ & $\begin{array}{l}\text { Reference } \\
1.0(0.4-2.5)\end{array}$ & 0.99 \\
\hline Self-reported history of seeing worms in the stool & $18(16.4)$ & $8(53.3)$ & $4.4(1.7-10.9)$ & 0.003 \\
\hline Raised in rural environment & $19(17.3)$ & $3(20)$ & $1.2(0.4-3.8)$ & 0.73 \\
\hline \multicolumn{5}{|l|}{ Laboratory results } \\
\hline IgE, number elevated ${ }^{\mathrm{c}}(\%)$ & $22(20)$ & $7(46.7)$ & $3.5(1.4-8.8)$ & 0.04 \\
\hline AEC, number elevated ${ }^{\mathrm{d}}(\%)$ & $9(8.3)^{\mathrm{e}}$ & $3(20)$ & $2.4(0.8-7.2)$ & 0.2 \\
\hline $\begin{array}{l}\text { Blastocystis hominis cysts } \\
\text { present on O\&P exam }\end{array}$ & $5\left(5.1^{\mathrm{f}}\right)$ & $5\left(38.5^{\mathrm{g}}\right)$ & $6.3(2.5-15.7)$ & 0.002 \\
\hline
\end{tabular}

$N$ number of subjects

${ }^{a}$ Not including nonpathogenic or disputed pathogenicity organisms

${ }^{\mathrm{b}}$ Prevalence ratio comparing the frequency of the listed demographic variable, symptom, or exposure in those with versus those without evidence of a parasitic infection

${ }^{\mathrm{c}}$ Normal value of $\mathrm{IgE}<696 \mathrm{IU} / \mathrm{mL}$ for subjects $10-12$ years old, $<629$ for those ages $13-15,<537$ for those ages $16-17$, and $<214 \mathrm{IU} / \mathrm{mL}$ in adults

${ }^{\mathrm{d}}$ Normal $\mathrm{AEC}<500$ cells/UL

${ }^{\mathrm{e}} \mathrm{Of} 108$ subjects in the uninfected group who were tested for a $\mathrm{CBC}$ (as for 2 patients who underwent a blood draw, the $\mathrm{CBC}$ was unable to be performed due to clotting of blood in the tube)

${ }^{\mathrm{f}}$ Of 98 subjects in the uninfected group who provided a stool sample for O\&P exam

${ }^{\mathrm{g}}$ Of 13 subjects in this group who provided a stool sample for O\&P exam

infection and risk for developing hyperinfection syndrome (Posey et al. 2007; Vadlamudi et al. 2006). The rate of seropositivity for strongyloidiasis in our sample was $4 \%$. This may have clinical implications because a study evaluating the cost-effectiveness of empiric treatment versus a test-and-treat strategy found that if the prevalence of Strongyloides infection is greater than $2 \%$ in a community, then the presumptive treatment strategy is more costeffective (Muennig et al. 2004). However, whether this strategy would still be cost-effective today is not clear and merits further study. Additionally, in areas with a large number of West African immigrants, this treatment strategy would not be possible due to concerns of coinfection with Loa loa.

Our results highlight the limitations of current diagnostic tests for parasitic infections. For example, the sensitivity of O\&P exam compared to qPCR testing (which is not yet universally available) for pathogenic parasites was very poor. While this could represent false positive qPCR tests, previous use of these tests in other studies has indicated a low rate of false positives (Cimino et al. 2015; Hochberg et al. 2011; Mejia et al. 2013; Winsberg et al. 1975). An additional limitation of diagnostics for parasites is that, for many parasitic infections, serologic testing is the primary commercially available means of diagnosis. Positive serologic testing is not proof of an active infection, so the utility of this information in treating an individual patient is limited.

Similar to prior studies of immigrant populations (Belhassen-Garcia et al. 2014; Schulte et al. 2002), we found that a relatively high percent of subjects in our study had eosinophilia and/or elevated $\operatorname{IgE}$ levels. $\operatorname{IgE}$ appeared to be a slightly better marker for chronic parasitic infection in this sample than eosinophilia. Prior studies have shown that for some parasites (such as Toxocara), specific anti-parasite $\operatorname{IgE}$ may be an even better diagnostic marker (Magnaval et al. 2006). However, neither the AEC nor the IgE had an adequate sensitivity to merit recommending their use for routine screening purposes. Although eosinophilia has long been thought of as a hallmark of helminth infection, several previous studies have also failed to show any correlation between the two (Asgary et al. 2011; Dawson-Hahn et al. 2010).

A large number of subjects in our study demonstrated cysts of $B$. hominis on O\&P exam. The association between B. hominis and clinical disease has been 
controversial. Various studies have shown that subjects with $B$. hominis may have an increased likelihood of irritable bowel syndrome and that symptomatic patients with this parasite may experience a beneficial effect from treatment with antiparasitic medications (Andersen and Stensvold 2016; Coyle et al. 2012). In our study, however, infection with $B$. hominis was not associated with any increase in symptoms. Interestingly, though, subjects with $B$. hominis cysts on O\&P exam were more likely to also test positive for pathogenic parasitic infections. Therefore, our results agree with those of several recent studies and suggest that the primary import of $B$. hominis infection may be serving as a surrogate marker for the presence of fecal-oral transmission (Coyle et al. 2012; Roberts et al. 2014; Turkeltaub et al. 2015).

Our study had several limitations. The small number of subjects found to have parasitic infections limited our ability to identify risk factors associated with these infections. However, our sample size was necessitated by the extensive testing performed on each subject and was also similar to those of previous studies of immigrant health (Hochberg et al. 2011; Loutfy et al. 2002). Furthermore, the fact that our sample was very heterogeneous and subjects enrolled in the study came from many different countries could have reduced our ability to find associations between clinical factors and the presence of infection. We chose to include subjects from many different countries because the goal of the study was to evaluate if parasitic infections are a potential health problem within immigrant communities in general.

Our study is one of the only recent studies to evaluate if parasitic infections currently pose health threats among immigrant communities. Our results provide an argument for further investigation of the health impacts of these infections in the immigrant community. Although our sample size was limited, a strength of our study is that we conducted a comprehensive evaluation for parasitic infections including testing of both stool and serum samples with novel molecular tests. Our results suggest that as many as $12 \%$ of recent immigrants in the community may have evidence of current or previous infection with a pathogenic parasitic species. From a public health perspective, it is important to note that the infections identified in the current patient sample are not typically spread from person to person. If confirmed in a larger study, these results present an important health disparity among a vulnerable underserved population in the USA. This health disparity has persisted despite the presence of effective, safe, and welltolerated antiparasitic medications capable of treating each of the identified pathogens in our sample (Muennig et al. 2004; Posey et al. 2007).

Acknowledgments The authors would like to thank E. Scott Elder BS, Isabel McAuliffe $\mathrm{PhD}$, and Sukwan Handali MD from the Centers for Disease Control and Prevention who performed the serologic assays conducted on patient samples. JH would like to thank Ed Mitre MD from USUHS and Thomas Nutman MD and Amy Klion MD from the National Institutes of Health (NIH) for input and help with the study design process. We also would like to thank the free clinics and social services organizations for collaborating with us and providing help with study recruitment.

Funding information Dr. Herrick's research was supported by the National Center for Advancing Translational Sciences and National Institutes of Health, through Grant UL1TR000050. Research funding support for RM was provided by the US Department of Health and Human Services and Health Resources and Services Administration for Baylor College of Medicine Center of Excellence in Health Equity, Training, and Research (Grant No: D34HP31024). RM has also received some funding support from Romark Laboratory.

Data availability All data generated or analyzed during this study are included in this published article and its supplementary information files.

\section{Compliance with ethical standards}

Conflict of interest The authors declare they have no conflicts of interest. The content is solely the responsibility of the authors and does not necessarily represent the official views of the NIH. The funders had no role in the study design, data collection and analysis, decision to publish, or preparation of the manuscript.

Ethical approval All procedures performed in studies involving human participants were in accordance with the ethical standards of the institutional research committee (the Institutional Review Board of the University of Chicago at Illinois) and with the 1964 Helsinki Declaration and its later amendments or comparable ethical standards.

Open Access This article is licensed under a Creative Commons Attribution 4.0 International License, which permits use, sharing, adaptation, distribution and reproduction in any medium or format, as long as you give appropriate credit to the original author(s) and the source, provide a link to the Creative Commons licence, and indicate if changes were made. The images or other third party material in this article are included in the article's Creative Commons licence, unless indicated otherwise in a credit line to the material. If material is not included in the article's Creative Commons licence and your intended use is not permitted by statutory regulation or exceeds the permitted use, you will need to obtain permission directly from the copyright holder. To view a copy of this licence, visit http://creativecommons.org/licenses/by/4.0/.

\section{References}

Adams DA et al (2017) Summary of notifiable infectious diseases and conditions - United States, 2015. MMWR Morb Mortal Wkly Rep 64:1-143. https://doi.org/10.15585/mmwr.mm6453a1

Affranchino JL et al (1989) Identification of a Trypanosoma cruzi antigen that is shed during the acute phase of Chagas' disease. Mol Biochem Parasitol 34:221-228

Andersen LO, Stensvold CR (2016) Blastocystis in health and disease: are we moving from a clinical to a public health perspective? J Clin Microbiol 54:524-528. https://doi.org/10.1128/JCM.02520-15

Anderson JP et al (2015) Development of a Luminex bead based assay for diagnosis of toxocariasis using recombinant antigens Tc-CTL-1 and Tc-TES-26. PLoS Negl Trop Dis 9:e0004168. https://doi.org/10. 1371/journal.pntd.0004168 
Arena R, Mathews CE, Kim AY, Lenz TE, Southern PM (2011) Prevalence of antibody to Trypanosoma cruzi in Hispanicsurnamed patients seen at Parkland Health \& Hospital System, Dallas, Texas. BMC Res Notes 4:132. https://doi.org/10.1186/ 1756-0500-4-132

Asgary R, Naderi R, Swedish KA, Smith CL, Sckell B, Doorley S (2011) Communicable and non-communicable diseases among recent immigrants with implications for primary care; a comprehensive immigrant health approach. J Immigr Minor Health 13:990-995. https://doi.org/10.1007/s10903-011-9476-3

Bass JL, Mehta KA, Eppes B (1992) Parasitology screening of Latin American children in a primary care clinic. Pediatrics 89:279-283

Belhassen-Garcia M et al (2014) Relevance of eosinophilia and hyperIgE in immigrant children. Medicine (Baltimore) 93:e43. https://doi. org/10.1097/MD.0000000000000043

Bern C, Montgomery SP (2009) An estimate of the burden of Chagas disease in the United States. Clin Infect Dis 49:e52-e54. https://doi. org/10.1086/605091

Bern C, Montgomery SP, Katz L, Caglioti S, Stramer SL (2008) Chagas disease and the US blood supply. Curr Opin Infect Dis 21:476-482. https://doi.org/10.1097/QCO.0b013e32830ef5b6

Bern C, Kjos S, Yabsley MJ, Montgomery SP (2011) Trypanosoma cruzi and Chagas disease in the United States. Clin Microbiol Rev 24: 655-681. https://doi.org/10.1128/CMR.00005-11

Buijs J, Borsboom G, Renting M, Hilgersom WJ, van Wieringen JC, Jansen G, Neijens J (1997) Relationship between allergic manifestations and toxocara seropositivity: a cross-sectional study among elementary school children. Eur Respir J 10:1467-1475

Chagatest ELISA recombinante v.3.0 Wiener lab. (2004, February 11). Retrieved from https://www.accessdata.fda.gov/cdrh_docs/pdf2/ k023889.pdf

Cimino RO, Jeun R, Juarez M, Cajal PS, Vargas P, Echazú A, Bryan PE, Nasser J, Krolewiecki A, Mejia R (2015) Identification of human intestinal parasites affecting an asymptomatic peri-urban Argentinian population using multi-parallel quantitative real-time polymerase chain reaction. Parasites Vectors 8:380. https://doi.org/ 10.1186/s13071-015-0994-Z

Cobzaru RG, Ripa C, Leon MM, Luca MC, Ivan A, Luca M (2012) Correlation between asthma and toxocara canis infection. Rev Med Chir Soc Med Nat Iasi 116:727-730

Conners EE, Vinetz JM, Weeks JR, Brouwer KC (2016) A global systematic review of Chagas disease prevalence among migrants. Acta Trop 156:68-78. https://doi.org/10.1016/j.actatropica.2016.01.002

Coyle CM, Varughese J, Weiss LM, Tanowitz HB (2012) Blastocystis: to treat or not to treat. Clin Infect Dis 54:105-110. https://doi.org/10. 1093/cid/cir810

Crum NF, Chun HM, Favata MA, Hale BR (2003) Gastrointestinal Schistosomiasis japonicum infections in immigrants from the island of Leyte, Philippines. J Travel Med 10:131-132

da Silveira JF, Umezawa ES, Luquetti AO (2001) Chagas disease: recombinant Trypanosoma cruzi antigens for serological diagnosis. Trends Parasitol 17:286-291

Dawson-Hahn EE, Greenberg SL, Domachowske JB, Olson BG (2010) Eosinophilia and the seroprevalence of schistosomiasis and strongyloidiasis in newly arrived pediatric refugees: an examination of Centers for Disease Control and Prevention screening guidelines. J Pediatr 156:1016-1018, 1018 e1011. https://doi.org/10.1016/j. jpeds.2010.02.043

Ezeamama AE et al (2005) Helminth infection and cognitive impairment among Filipino children. Am J Trop Med Hyg 72:540-548

Fitzpatrick MA, Caicedo JC, Stosor V, Ison MG (2010) Expanded infectious diseases screening program for Hispanic transplant candidates. Transpl Infect Dis 12:336-341. https://doi.org/10.1111/j.1399-3062. 2010.00517.x
Garg PK, Perry S, Dorn M, Hardcastle L, Parsonnet J (2005) Risk of intestinal helminth and protozoan infection in a refugee population. Am J Trop Med Hyg 73:386-391

Hancock K, Tsang VC (1986) Development and optimization of the FAST-ELISA for detecting antibodies to Schistosoma mansoni. J Immunol Methods 92:167-176

Hernandez-Gonzalez A, Noh J, Perteguer MJ, Garate T, Handali S (2017) Comparison of T24H-his, GST-T24H and GST-Ts8B2 recombinant antigens in western blot, ELISA and multiplex bead-based assay for diagnosis of neurocysticercosis. Parasites Vectors 10:237. https:// doi.org/10.1186/s13071-017-2160-2

Hochberg NS, Moro RN, Sheth AN, Montgomery SP, Steurer F, McAuliffe I, Wang YF, Armstrong W, Rivera HN, Lennox JL, Franco-Paredes C (2011) High prevalence of persistent parasitic infections in foreign-born, HIV-infected persons in the United States. PLoS Negl Trop Dis 5:e1034. https://doi.org/10.1371/ journal.pntd.0001034

Hotez PJ (2007) Neglected diseases and poverty in "The Other America": the greatest health disparity in the United States? PLoS Negl Trop Dis 1:e149. https://doi.org/10.1371/journal.pntd.0000149

Hotez PJ (2008) Neglected infections of poverty in the United States of America. PLoS Negl Trop Dis 2:e256. https://doi.org/10.1371/ journal.pntd.0000256

Hotez PJ (2014) Neglected parasitic infections and poverty in the United States. PLoS Negl Trop Dis 8:e3012. https://doi.org/10.1371/ journal.pntd.0003012

Hotez PJ, Bottazzi ME, Dumonteil E, Valenzuela JG, Kamhawi S, Ortega J, Rosales SP, Cravioto MB, Tapia-Conyer R (2012) Texas and Mexico: sharing a legacy of poverty and neglected tropical diseases. PLoS Negl Trop Dis 6:e1497. https://doi.org/10.1371/journal.pntd. 0001497

Jariwala S, Redding L, Hewitt D (2017) The severely under-recognized public health risk of strongyloidiasis in North American cities-a one health approach. Zoonoses Public Health. https://doi.org/10.1111/ zph. 12371

Jourdan PM, Lamberton PHL, Fenwick A, Addiss DG (2017) Soiltransmitted helminth infections. Lancet. https://doi.org/10.1016/ S0140-6736(17)31930-X

Kanobana K, Vereecken K, Junco Diaz R, Sariego I, Rojas L, Bonet Gorbea M, Polman K (2013) Toxocara seropositivity, atopy and asthma: a study in Cuban schoolchildren. Trop Med Int Health. https://doi.org/10.1111/tmi.12073

Khurana S, Sethi S (2017) Laboratory diagnosis of soil transmitted helminthiasis. Trop Parasitol 7:86-91. https://doi.org/10.4103/tp.TP 29 17

Leiby DA, Herron RM Jr, Read EJ, Lenes BA, Stumpf RJ (2002) Trypanosoma cruzi in Los Angeles and Miami blood donors: impact of evolving donor demographics on seroprevalence and implications for transfusion transmission. Transfusion 42:549-555

Liu EW, Chastain HM, Shin SH, Wiegand RE, Kruszon-Moran D, Handali S, Jones JL (2018) Seroprevalence of antibodies to toxocara species in the United States and associated risk factors, 2011-2014. Clin Infect Dis 66:206-212. https://doi.org/10.1093/cid/cix784

Loutfy MR, Wilson M, Keystone JS, Kain KC (2002) Serology and eosinophil count in the diagnosis and management of strongyloidiasis in a non-endemic area. Am J Trop Med Hyg 66:749-752

Maddison SE (1991) Serodiagnosis of parasitic diseases. Clin Microbiol Rev 4:457-469

Magnaval JF, Faufingue JH, Morassin B, Fabre R (2006) Eosinophil cationic protein, specific IgE and IgG4 in human toxocariasis. $\mathrm{J}$ Helminthol 80:417-423. https://doi.org/10.1017/joh2006369

Manne-Goehler J, Umeh CA, Montgomery SP, Wirtz VJ (2016) Estimating the burden of Chagas disease in the United States. PLoS Negl Trop Dis 10:e005033. https://doi.org/10.1371/journal. pntd.0005033 
McKenna ML et al (2017) Human intestinal parasite burden and poor sanitation in rural Alabama. Am J Trop Med Hyg 97:1623-1628. https://doi.org/10.4269/ajtmh.17-0396

Mejia R et al (2013) A novel, multi-parallel, real-time polymerase chain reaction approach for eight gastrointestinal parasites provides improved diagnostic capabilities to resource-limited at-risk populations. Am J Trop Med Hyg 88:1041-1047. https://doi.org/10. 4269/ajtmh.12-0726

Meymandi SK, Hernandez S, Forsyth CJ (2017) A community-based screening program for Chagas disease in the USA. Trends Parasitol 33:828-831. https://doi.org/10.1016/j.pt.2017.07.003

Moncayo A, Ortiz Yanine MI (2006) An update on Chagas disease (human American trypanosomiasis). Ann Trop Med Parasitol 100:663677. https://doi.org/10.1179/136485906X112248

Muennig P, Pallin D, Challah C, Khan K (2004) The cost-effectiveness of ivermectin vs. albendazole in the presumptive treatment of strongyloidiasis in immigrants to the United States. Epidemiol Infect 132: 1055-1063

Ndao M (2009) Diagnosis of parasitic diseases: old and new approaches. Interdiscip Perspect Infect Dis 2009:278246. https://doi.org/10. $1155 / 2009 / 278246$

Ostera G, Blum J (2016) Strongyloidiasis: Risk and healthcare access for Latin American immigrants living in the United States. Curr Trop Med Rep 3:1-3. https://doi.org/10.1007/s40475-016-0065-3

Ostera G, Blum J, Cornejo C, Burgula S, Jeun R, Bryan PE, Mejia R (2017) Strongyloidiasis in Latin American immigrants: a pilot study. J Helminthol 91:262-266. https://doi.org/10.1017/ S0022149X16000213

Parise ME, Hotez PJ, Slutsker L (2014) Neglected parasitic infections in the United States: needs and opportunities. Am J Trop Med Hyg 90: 783-785. https://doi.org/10.4269/ajtmh.13-0727

Perez-Molina JA, Norman F, Lopez-Velez R (2012) Chagas disease in non-endemic countries: epidemiology, clinical presentation and treatment. Curr Infect Dis Rep 14:263-274. https://doi.org/10. 1007/s11908-012-0259-3

Posey DL et al (2007) High prevalence and presumptive treatment of schistosomiasis and strongyloidiasis among African refugees. Clin Infect Dis 45:1310-1315. https://doi.org/10.1086/522529

Rapoport AB, McCormick D, Cohen PA (2015) Screening for Schistosoma mansoni and Strongyloides stercoralis infection among Brazilian immigrants in the United States. Open Forum Infect Dis 2: ofv003. https://doi.org/10.1093/ofid/ofv003

Rascoe LN, Price C, Shin SH, McAuliffe I, Priest JW, Handali S (2015) Development of Ss-NIE-1 recombinant antigen based assays for immunodiagnosis of strongyloidiasis. PLoS Negl Trop Dis 9: e0003694. https://doi.org/10.1371/journal.pntd.0003694

Roberts T, Stark D, Harkness J, Ellis J (2014) Update on the pathogenic potential and treatment options for Blastocystis sp. Gut Pathog 6:17. https://doi.org/10.1186/1757-4749-6-17

Safdar A, Malathum K, Rodriguez SJ, Husni R, Rolston KV (2004) Strongyloidiasis in patients at a comprehensive cancer center in the United States. Cancer 100:1531-1536. https://doi.org/10.1002/ cncr.20120
Sarkar S, Strutz SE, Frank DM, Rivaldi CL, Sissel B, Sanchez-Cordero V (2010) Chagas disease risk in Texas. PLoS Negl Trop Dis 4. https:// doi.org/10.1371/journal.pntd.0000836

Schmunis GA, Yadon ZE (2010) Chagas disease: a Latin American health problem becoming a world health problem. Acta Trop 115: 14-21. https://doi.org/10.1016/j.actatropica.2009.11.003

Schulte C, Krebs B, Jelinek T, Nothdurft HD, von Sonnenburg F, Loscher $\mathrm{T}$ (2002) Diagnostic significance of blood eosinophilia in returning travelers. Clin Infect Dis 34:407-411. https://doi.org/10.1086/ 338026

Shulman IA, Appleman MD, Saxena S, Hiti AL, Kirchhoff LV (1997) Specific antibodies to Trypanosoma cruzi among blood donors in Los Angeles, California. Transfusion 37:727-731

Starr MC, Montgomery SP (2011) Soil-transmitted Helminthiasis in the United States: a systematic review-1940-2010x. Clin Infect Dis 34: 407-411. https://doi.org/10.4269/ajtmh.2011.11-0214

Tsang VC, Wilkins PP (1991) Immunodiagnosis of schistosomiasis. Screen with FAST-ELISA and confirm with immunoblot. Clin Lab Med 11:1029-1039

Tsang VC, Wilkins PP (1997) Immunodiagnosis of schistosomiasis. Immunol Investig 26:175-188

Turkeltaub JA, McCarty TR 3rd, Hotez PJ (2015) The intestinal protozoa: emerging impact on global health and development. Curr Opin Gastroenterol 31:38-44. https://doi.org/10.1097/MOG. 0000000000000135

Vadlamudi RS, Chi DS, Krishnaswamy G (2006) Intestinal strongyloidiasis and hyperinfection syndrome. Clin Mol Allergy 4:8. https://doi. org/10.1186/1476-7961-4-8

Walsh MG (2011) Toxocara infection and diminished lung function in a nationally representative sample from the United States population. Int J Parasitol 41:243-247. https://doi.org/10.1016/j.ijpara.2010.09. 006

Weatherhead J, Cortés AA, Sandoval C, Vaca M, Chico M, Loor S, Cooper PJ, Mejia R (2017) Comparison of cytokine responses in Ecuadorian children infected with Giardia, Ascaris, or Both Parasites. Am J Trop Med Hyg 96:1394-1399. https://doi.org/10. 4269/ajtmh.16-0580

Winsberg GR, Sonnenschein E, Dyer AR, Schnadig V, Bonilla E (1975) Prevalence of intestinal parasites in Latino residents of Chicago. Am J Epidemiol 102:526-532

Won KY, Kruszon-Moran D, Schantz PM, Jones JL (2008) National seroprevalence and risk factors for zoonotic Toxocara spp. infection. Am J Trop Med Hyg 79:552-557

Yap P, Furst T, Muller I, Kriemler S, Utzinger J, Steinmann P (2012) Determining soil-transmitted helminth infection status and physical fitness of school-aged children. J Vis Exp e3966. https://doi.org/10. 3791/3966

Zaniello BA, Kessler DA, Vine KM, Grima KM, Weisenberg SA (2012) Seroprevalence of Chagas infection in the donor population. PLoS Negl Trop Dis 6:e1771. https://doi.org/10.1371/journal.pntd. 0001771

Publisher's note Springer Nature remains neutral with regard to jurisdictional claims in published maps and institutional affiliations. 